\title{
Cerium Dioxide Thin Films Using Spin Coating
}

\author{
D. Channei, ${ }^{1,2}$ A. Nakaruk, ${ }^{2}$ S. Phanichphant, ${ }^{3}$ P. Koshy, ${ }^{2}$ and C. C. Sorrell ${ }^{2}$ \\ ${ }^{1}$ Department of Chemistry, Faculty of Science, Chiang Mai University, Chiang Mai 50200, Thailand \\ ${ }^{2}$ School of Materials Science and Engineering, University of New South Wales, Sydney, NSW 2052, Australia \\ ${ }^{3}$ Materials Science Research Center, Faculty of Science, Chiang Mai University, Chiang Mai 50200, Thailand
}

Correspondence should be addressed to S. Phanichphant; sphanichphant@yahoo.com

Received 22 June 2012; Accepted 23 August 2012

Academic Editor: Roberto Comparelli

Copyright (C) 2013 D. Channei et al. This is an open access article distributed under the Creative Commons Attribution License, which permits unrestricted use, distribution, and reproduction in any medium, provided the original work is properly cited.

\begin{abstract}
Cerium dioxide $\left(\mathrm{CeO}_{2}\right)$ thin films with varying Ce concentrations ( 0.1 to $0.9 \mathrm{M}$, metal basis) were deposited on soda-lime-silica glass substrates using spin coating. It was found that all films exhibited the cubic fluorite structure after annealing at $500^{\circ} \mathrm{C}$ for $5 \mathrm{~h}$. The laser Raman microspectroscopy and GAXRD analyses revealed that increasing concentrations of Ce resulted in an increase in the degree of crystallinity. FIB and FESEM images confirmed the laser Raman and GAXRD analyses results owing to the predicted increase in film thickness with increasing Ce concentration. However, porosity and shrinkage (drying) cracking of the films also increased significantly with increasing Ce concentrations. UV-VIS spectrophotometry data showed that the transmission of the films decreased with increasing Ce concentrations due to the increasing crack formation. Furthermore, a red shift was observed with increasing Ce concentrations, which resulted in a decrease in the optical indirect band gap.
\end{abstract}

\section{Introduction}

During the last few decades, metal oxide semiconductors have become important materials, with numerous publications focusing on different types of these materials namely, $\mathrm{In}_{2} \mathrm{O}_{3}, \mathrm{TiO}_{2}, \mathrm{SnO}_{2}$, and $\mathrm{CeO}_{2}$. Recently, there has been growing interest in the use of $\mathrm{CeO}_{2}[1-3]$ due to its promising characteristics, including: (i) it is an n-type semiconductor with a band gap of $3.2 \mathrm{eV}[4,5]$, (ii) it is highly transparent in the visible region $(400-800 \mathrm{~nm})[4,5]$, and (iii) it is inexpensive. These advantages enhance the potential for $\mathrm{CeO}_{2}$ to be used widely in a range of applications, such as oxygen storage [6], smart windows [7], electrochemical displays [8], UV filters [9], and catalysts [10]. For the preceding applications, thin film $\mathrm{CeO}_{2}$ is used most commonly owing to its flexibility of use, cost considerations, and ease of preparation.

$\mathrm{CeO}_{2}$ thin films can be prepared by several techniques, including spray pyrolysis [11], pulsed laser deposition [12], sputtering [13], and spin coating [14]. The latter is one of the most advantageous techniques owing to its versatility, effectiveness, and practicality. Furthermore, the operation can be done in ambient conditions and thus a vacuum system is not required.
The aim of this work was to prepare $\mathrm{CeO}_{2}$ thin films on soda-lime-silica glass substrates using spin coating and to investigate the mineralogy, morphology, and optical properties of these films.

\section{Methodology}

Solution precursors were prepared using cerium chloride heptahydrate (analytical grade, 99.9\%, Sigma Aldrich) dissolved in methanol (Reagent Plus $\geq 99 \mathrm{wt} \%$, Sigma-Aldrich) with magnetic stirring. The concentrations of Ce used were $0.10,0.30,0.50,0.70$, and $0.90 \mathrm{M}$ (metals basis). To each of these solutions $5 \mathrm{~mL}$ of citric acid were added $(0.2 \mathrm{M}$, analytical grade, 99.0 trace metal basis, Sigma Aldrich), followed by stirring at $500 \mathrm{rpm}$ for 5 minutes without heating. Spin coating (Laurell WS-65052) was done by rapidly depositing $\sim 0.2 \mathrm{~mL}$ (ten sequential drops) of solution onto a microscope slide spun at $2000 \mathrm{rpm}$ in air. The films were dried by spinning for an additional $15 \mathrm{~s}$. Subsequently, all the films were annealed at $500^{\circ} \mathrm{C}$ for $5 \mathrm{~h}$ in air in a muffle furnace (heating rate $300^{\circ} \mathrm{C} / \mathrm{h}$, natural cooling).

The mineralogies of the films were determined by glancing angle X-ray diffraction (GAXRD, Philips X'pert Materials 


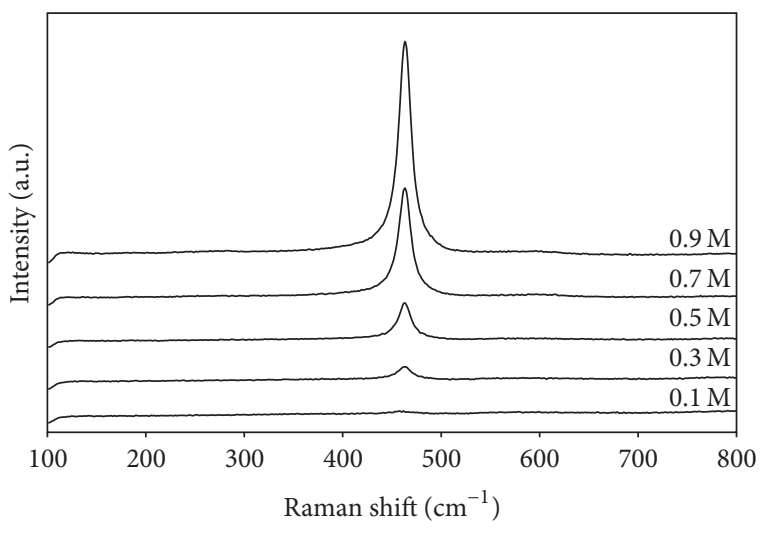

FIgURE 1: Laser Raman microspectra of $\mathrm{CeO}_{2}$ films prepared using solutions of varying Ce concentrations.

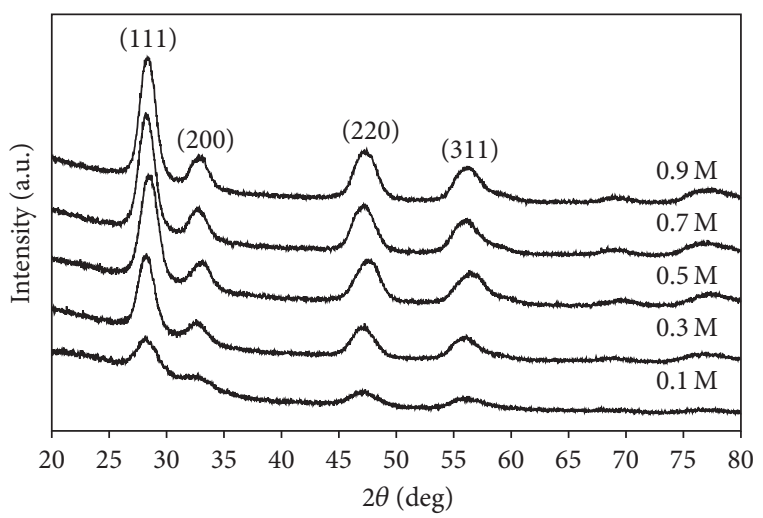

FIGURE 2: GAXRD patterns of $\mathrm{CeO}_{2}$ films prepared using solutions of varying Ce concentrations.

Research Diffraction, CuK $\alpha, 45 \mathrm{kV}, 40 \mathrm{~mA}$, step size $0.02^{\circ} 2 \theta$, speed $6^{\circ} / \mathrm{min} 2 \theta$ ) and laser Raman microspectroscopy (HeCd UV laser excitation source, wavelength $514 \mathrm{~nm}$, Renishaw inVia). The film thicknesses were determined using singlebeam focused ion beam (FIB) milling (FEI XP200). Fieldemission scanning electron microscopy (FESEM, Hitachi S4500; Cr-coated, secondary electron emission mode, $5 \mathrm{kV}$ accelerating voltage) was used to investigate the morphologies of the films. The transmissions in the ultraviolet-visible (UV-VIS) range were determined using a dual-beam spectrophotometer (Perkin Elmer Lambda 35) and the optical indirect band gap was calculated from these data using the method of Tauc and Menth [15] as shown by (1).

$$
\alpha=-\frac{1}{d} \ln (T) \cong A^{*}\left(h v-E_{g}\right)^{2}
$$

where $\alpha=$ absorption coefficient (obtained from light transmission and film thickness), $d=$ film thickness $(\mathrm{cm}), T=$ transmission (\%), $A^{*}=$ Constant that does not depend on $h v$, $h=$ Planck's constant $\left(4.135 \times 10^{-15} \mathrm{eV} \cdot \mathrm{s}\right), v=$ frequency $\left(\mathrm{s}^{-1}\right)$, $E_{g}=$ indirect band gap $(\mathrm{eV})$.

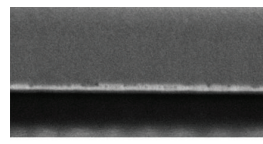

Ce $0.1 \mathrm{M}$

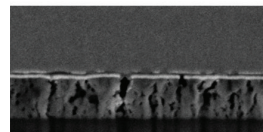

Ce $0.7 \mathrm{M}$

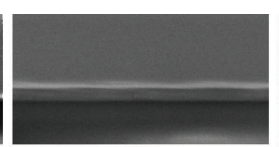

Ce $0.3 \mathrm{M}$

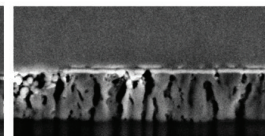

Ce $0.9 \mathrm{M}$

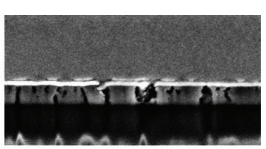

Ce $0.5 \mathrm{M}$

$\overline{500 \mathrm{~nm}}$
FIGURE 3: FIB images of the cross-sectional areas of the $\mathrm{CeO}_{2}$ films produced using solutions of varying Ce concentrations.

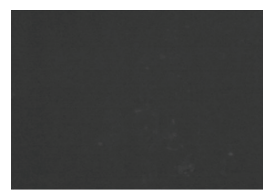

Ce $0.1 \mathrm{M}$

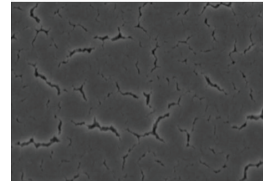

Ce $0.7 \mathrm{M}$

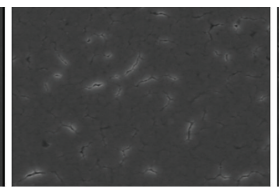

Ce $0.3 \mathrm{M}$

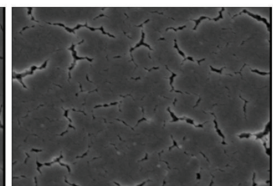

Ce $0.9 \mathrm{M}$

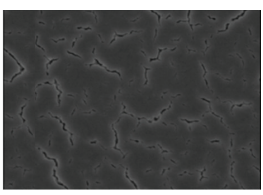

Ce $0.5 \mathrm{M}$

$\overline{1 \mu \mathrm{m}}$
FIGURE 4: FESEM images of the surface morphologies of $\mathrm{CeO}_{2}$ films prepared using solutions of varying Ce concentrations.

\section{Results and Discussion}

Figure 1 shows the laser Raman spectra of the films. These data clearly indicate that the peak intensity of $\mathrm{CeO}_{2}$ increased significantly with increasing Ce concentration. The GAXRD patterns of the films showed the same trend as the laser Raman microspectra, as seen from Figure 2. The increase in intensity of the laser Raman spectra and GAXRD patterns with increasing Ce concentration is the result of increasing amounts of material being deposited which consequently increased both the thickness of the films and the degree of crystallinity. Furthermore, the GAXRD patterns also confirm that all films exhibited the cubic fluorite structure [2] after annealing at $500^{\circ} \mathrm{C}$.

The FIB images, shown in Figure 3, show that the thickness of the films increased with increasing Ce concentrations, which confirms the results observed from the laser Raman and GAXRD analyses. It is also seen that, with increasing thickness of the films, the extent of porosity also increased. The average thicknesses of the films are listed in Table 1.

Figure 4 shows FESEM images showing the surface morphologies of the films. It can be seen that, with increasing Ce concentrations, the number and sizes of shrinkage cracks and resultant pores increased, similar to what was observed in the FIB images of the cross-sections. It is unknown if the cracks derive from shrinkage during drying or annealing. The increasing amount of shrinkage is consistent with both the increasing amounts of removed water (from the heptahydrate) and the increasing degree of crystallinity (since crystallisation is always accompanied by shrinkage). 
TABLE 1: Thicknesses and optical indirect band gaps of the different films.

\begin{tabular}{lcc}
\hline $\begin{array}{l}\text { Cerium } \\
\text { concentration }(\mathrm{M})\end{array}$ & $\begin{array}{c}\text { Average thickness } \\
(\mathrm{nm})\end{array}$ & $\begin{array}{c}\text { Optical indirect band } \\
\text { gap }(\mathrm{eV})\end{array}$ \\
\hline 0.1 & 100 & 3.85 \\
0.3 & 240 & 3.76 \\
0.5 & 380 & 3.67 \\
0.7 & 700 & 3.52 \\
0.9 & 840 & 3.46 \\
\hline
\end{tabular}

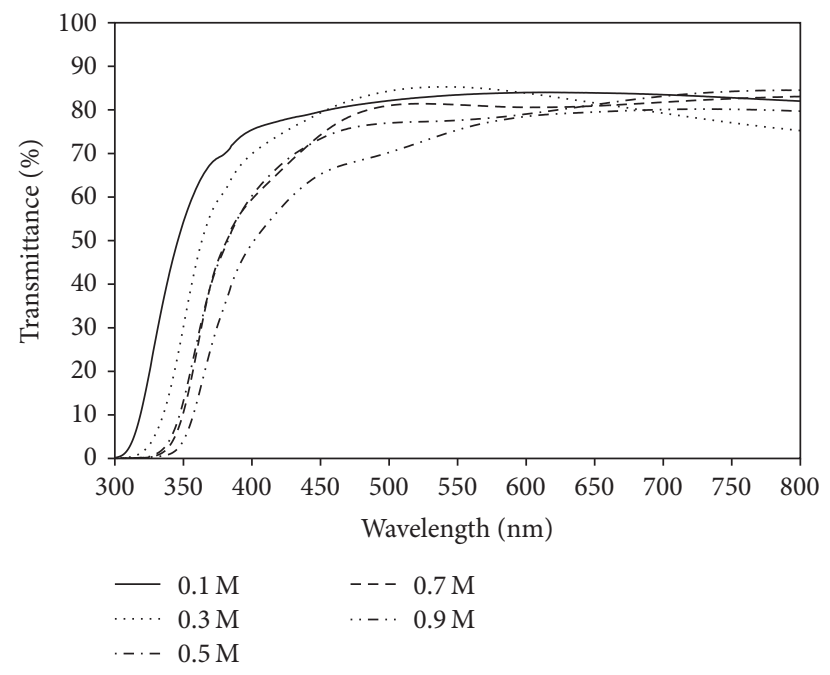

FIGURE 5: UV-VIS spectra of $\mathrm{CeO}_{2}$ films prepared using solutions of varying Ce concentrations.

Figure 5 shows the UV-VIS spectra of the films and it is seen that the transmission of the films decreased with increasing Ce concentrations in the films. Moreover, the absorption edge shifted towards longer wavelengths (red shift). The increase in the thickness and light scattering from pores/cracks are responsible for the observed decrease of the transmission spectra [16-18].

Since, $\mathrm{CeO}_{2}$ is known to be a transparent conductive oxide, a polycrystalline $\mathrm{CeO}_{2}$ thin film is transparent to visible light ( $400-800 \mathrm{~nm})$. However, Figure 5 shows that the transmission in visible region slightly decreased. The possible explanation for this observance is that with increasing $\mathrm{Ce}$ concentration, there was a drastic increase in the porosity and crack formation in the films (as shown in Figures 3 and 4). These imperfections enhance the light scattered by the films and thereby decreases the light transmitted through the films. Additionally, in the ultraviolet region $(>400 \mathrm{~nm})$, a significant red shift is observed with increasing Ce concentrations. This red shift is associated with the decrease of the indirect band gap of the films.

The optical indirect band gaps of the films were calculated using the UV-VIS data; the details are described elsewhere [15]. The data, shown in Table 1, demonstrated that the optical indirect band gaps decreased significantly with increasing
Ce concentrations and this is attributed to the increasing crystallinity of the films.

\section{Summary and Conclusions}

$\mathrm{CeO}_{2}$ thin films were deposited on soda-lime-silica glass substrates by spin coating using methanol solutions of varying Ce concentrations $(0.1$ to $0.9 \mathrm{M})$. The major conclusions of the present work are as follows.

(i) All the films exhibited the cubic fluorite structure phase after annealing at $500^{\circ} \mathrm{C}$ for $5 \mathrm{~h}$.

(ii) The laser Raman microspectroscopy and GAXRD analyses showed that with increasing Ce concentration, the thicknesses of the films increased as did their degree of crystallinity.

(iii) The FIB images confirmed the increasing film thicknesses and the FESEM images showed increasing porosity and cracking with increasing Ce concentration in the films.

(iv) UV-VIS spectra showed that the transmittance of the films decreased with increasing Ce concentration and hence the observation of a red shift, which decreased the optical indirect band gap.

The present work shows that crystalline $\mathrm{CeO}_{2}$ films as thin as $\sim 100 \mathrm{~nm}$ can be produced by spin coating and by annealing at $500^{\circ} \mathrm{C}$. The thicknesses of the films can be controlled through modification of the Ce concentration. Further work is required in reducing the cracking of the films by controlling the rates of drying and/or heating (during annealing). While this is relatively easy in the latter case, the former would likely require imposition of a water-vapour-saturated atmosphere in the spin coater chamber, which would put the electronics of the unit at risk. Alternatively, longer chain alcohol solvents could be used but these would cause greater annealing shrinkages. Ultimate success is likely to require the appropriate combination of cerium salt, solvent, film thickness, drying rate, annealing rate, and annealing temperature.

\section{Acknowledgments}

D. Channei gratefully acknowledges the financial support of the Royal Golden Jubilee Ph.D. Program (RGJ), Thailand Research Funds, the National Research University, Thailand Office of Higher Education Commission, and the Department and Graduate School of Chemistry, Chiang Mai University. The authors also would like to acknowledge the financial support of the Australian Research Council and the UNSW node of the Australian Microscopy \& Microanalysis Research Facility (AMMRF).

\section{References}

[1] V. Mihalache and I. Pasuk, "Grain growth, microstructure and surface modification of textured $\mathrm{CeO}_{2}$ thin films on $\mathrm{Ni}$ substrate," Acta Materialia, vol. 59, no. 12, pp. 4875-4885, 2011.

[2] P. J. King, M. Werner, P. R. Chalker et al., "Effect of deposition temperature on the properties of $\mathrm{CeO}_{2}$ films grown by 
atomic layer deposition," Thin Solid Films, vol. 519, no. 13, pp. 4192-4195, 2011.

[3] A. Khare, R. J. Choudhary, D. M. Phase, and S. P. Sanyal, "Electronic structure studies of $\mathrm{Fe}$ doped $\mathrm{CeO}_{2}$ thin films by resonance photoemission spectroscopy," Journal of Applied Physics, vol. 109, no. 12, Article ID 123706, 2011.

[4] C. Mansilla, "Structure, microstructure and optical properties of cerium oxide thin films prepared by electron beam evaporation assisted with ion beams," Solid State Sciences, vol. 11, no. 8, pp. 1456-1464, 2009.

[5] G. Balakrishnan, P. Kuppusami, T. N. Sairam, R. Thirumurugesan, E. Mohandas, and D. Sastikumar, "Synthesis and properties of ceria thin films prepared by pulsed laser deposition," Journal of Nanoscience and Nanotechnology, vol. 9, no. 9, pp. 5421-5424, 2009.

[6] J. Wang, B. Zhang, M. Shen et al., "Effects of Fe-doping of ceriabased materials on their microstructural and dynamic oxygen storage and release properties," Journal of Sol-Gel Science and Technology, vol. 58, no. 1, pp. 259-268, 2011.

[7] A. Al-Kahlout, D. Vieira, C. O. Avellaneda, E. R. Leite, M. A. Aegerter, and A. Pawlicka, "Gelatin-based protonic electrolyte for electrochromic windows," Ionics, vol. 16, no. 1, pp. 13-19, 2010.

[8] D. Camino, D. Deroo, J. Salardenne, and N. Treuil, " $\left(\mathrm{CeO}_{2}\right)_{\mathrm{x}}-\left(\mathrm{TiO}_{2}\right)_{1-\mathrm{x}}$ : counter electrode materials for lithium electrochromic devices," Solar Energy Materials and Solar Cells, vol. 39, no. 2-4, pp. 349-366, 1995.

[9] J. F. D. Lima, R. F. Martins, C. R. Neri, and O. A. Serra, "ZnO: $\mathrm{CeO}_{2}$-based nanopowders with low catalytic activity as UV absorbers," Applied Surface Science, vol. 255, no. 22, pp. 9006-9009, 2009.

[10] A. Trovarelli, "Catalytic properties of ceria and $\mathrm{CeO}_{2}$ Containing materials," Catalysis Reviews, vol. 38, no. 4, pp. 439-520, 1996.

[11] B. B. Patil and S. H. Pawar, "Structural, morphological and electrical properties of spray deposited nano-crystalline $\mathrm{CeO}_{2}$ thin films," Journal of Alloys and Compounds, vol. 509, no. 2, pp. 414-420, 2011.

[12] G. Balakrishnan, S. T. Sundari, P. Kuppusami et al., "A study of microstructural and optical properties of nanocrystalline ceria thin films prepared by pulsed laser deposition," Thin Solid Films, vol. 519, no. 8, pp. 2520-2526, 2011.

[13] N. Savvides, A. Thorley, S. Gnanarajan, and A. Katsaros, "Epitaxial growth of cerium oxide thin film buffer layers deposited by d.c. magnetron sputtering," Thin Solid Films, vol. 388, no. 1-2, pp. 177-182, 2001.

[14] F. E. Ghodsi, F. Z. Tepehan, and G. G. Tepehan, "Influence of $\mathrm{pH}$ on the optical and structural properties of spin coated $\mathrm{CeO}_{2}$ $\mathrm{TiO}_{2}$ thin films prepared by sol-gel process," Surface Science, vol. 601, no. 18, pp. 4497-4501, 2007.

[15] J. Tauc and A. Menth, "States in the gap," Journal of NonCrystalline Solids, vol. 8-10, no. 1, pp. 569-585, 1972.

[16] A. Nakaruk, D. Ragazzon, and C. C. Sorrell, "Anatase-rutile transformation through high-temperature annealing of titania films produced by ultrasonic spray pyrolysis," Thin Solid Films, vol. 518, no. 14, pp. 3735-3742, 2010.

[17] A. Nakaruk, G. Kavei, and C. C. Sorrell, "Synthesis of mixedphase titania films by low-temperature ultrasonic spray pyrolysis," Materials Letters, vol. 64, no. 12, pp. 1365-1368, 2010.

[18] A. Nakaruk, D. Ragazzon, and C. C. Sorrell, "Anatase thin films by ultrasonic spray pyrolysis," Journal of Analytical and Applied Pyrolysis, vol. 88, no. 1, pp. 98-101, 2010. 

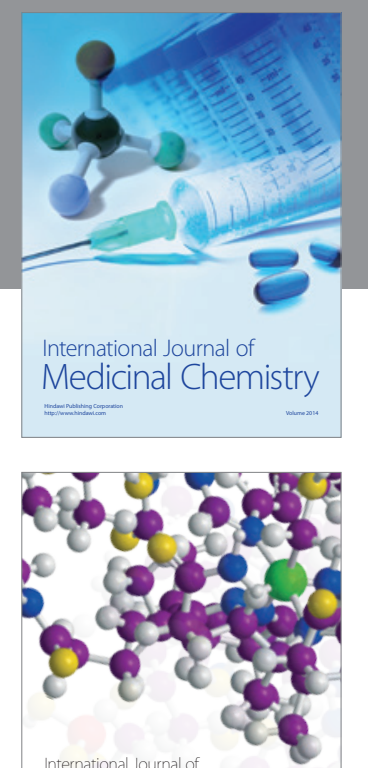

\section{Carbohydrate} Chemistry

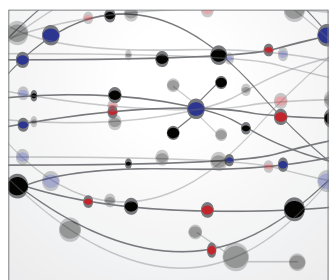

The Scientific World Journal
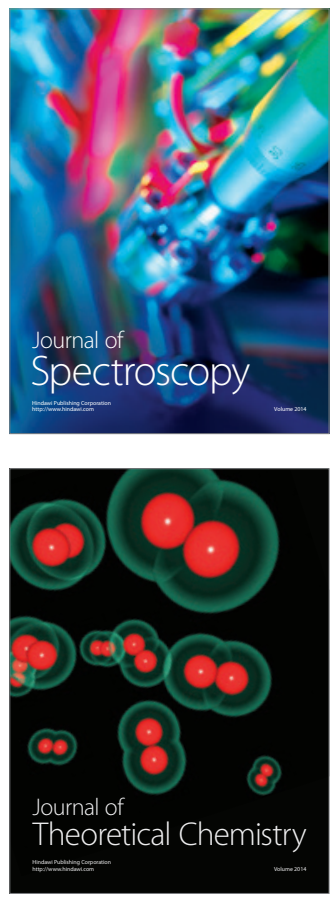
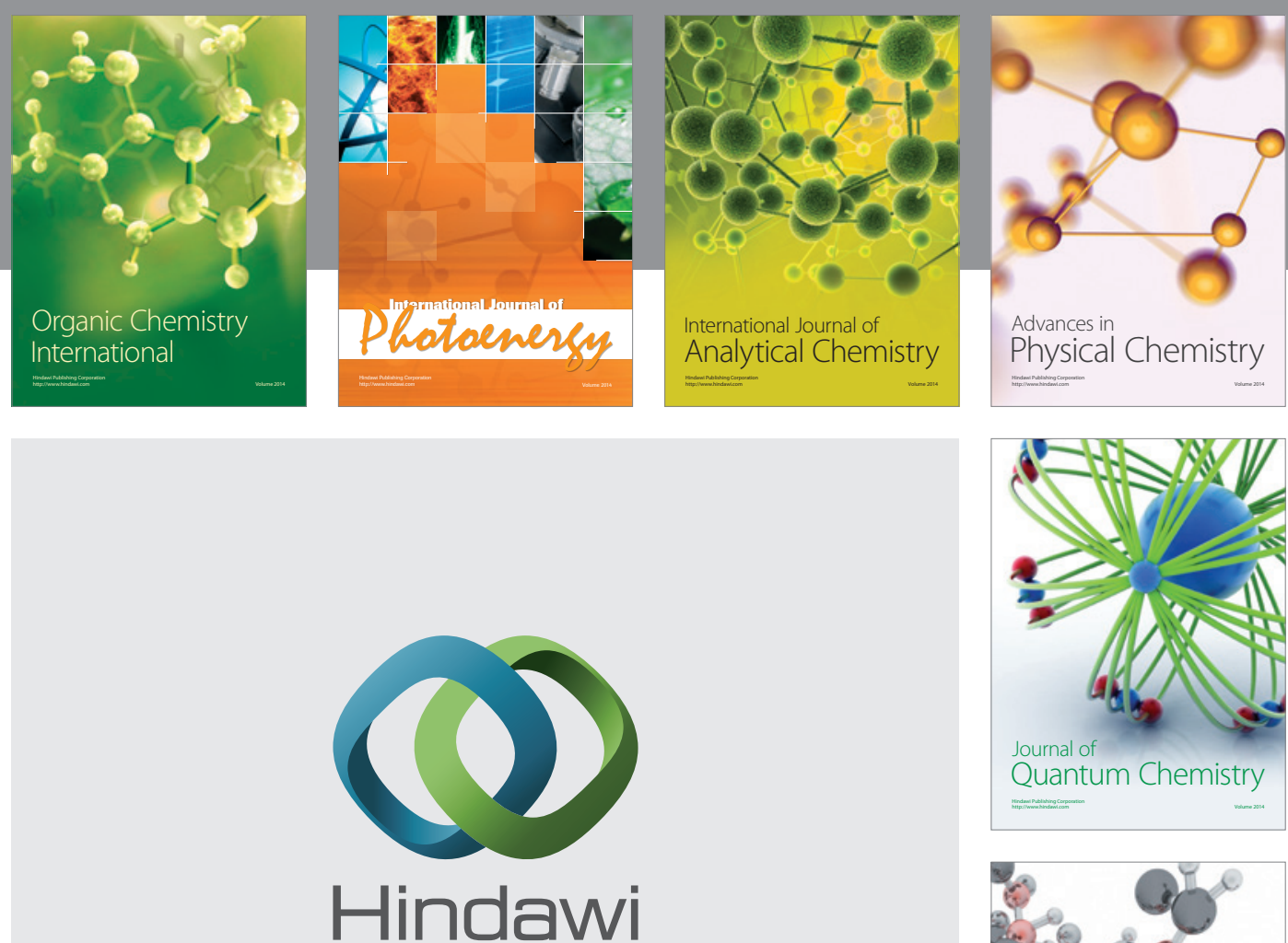

Submit your manuscripts at

http://www.hindawi.com

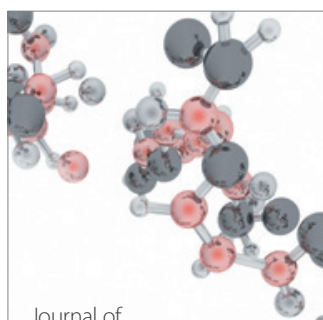

Analytical Methods

in Chemistry

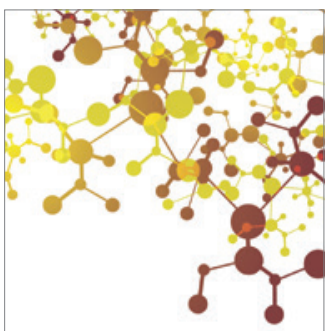

Journal of

Applied Chemistry

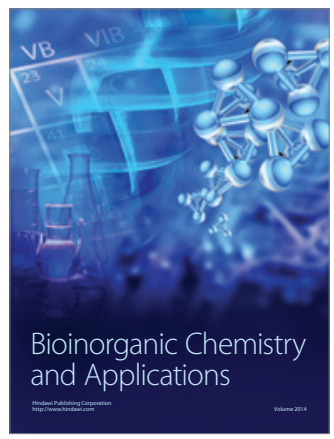

Inorganic Chemistry
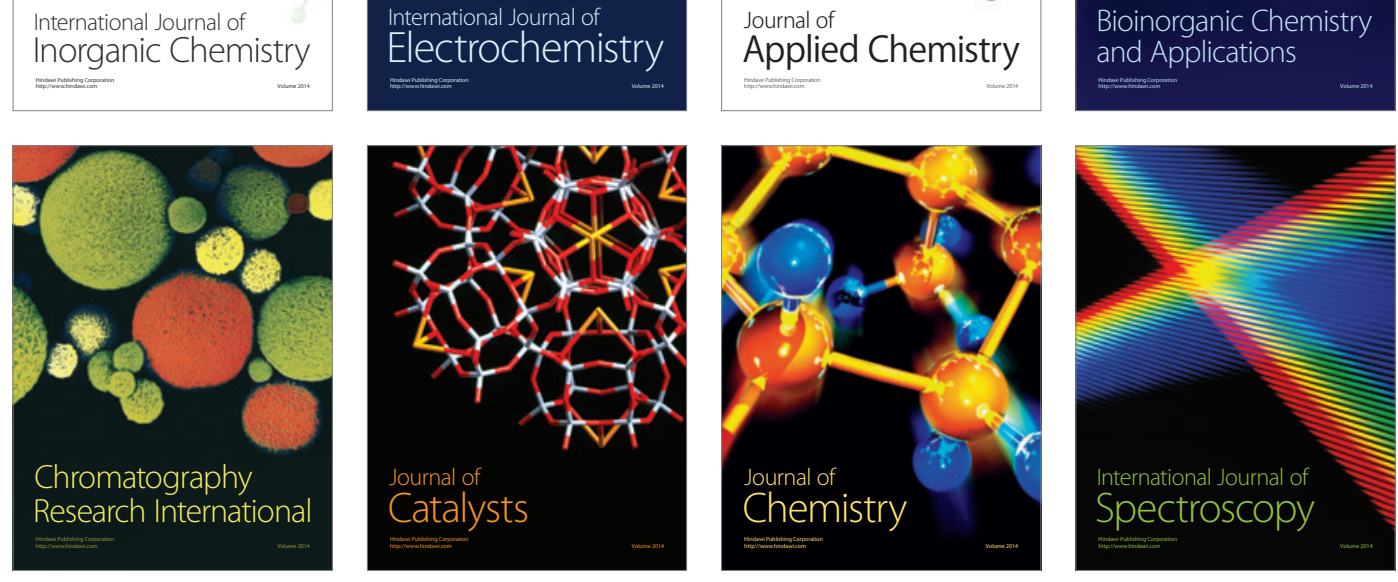